\title{
DEPLOYMENT, FOAM RIGIDIZATION, AND STRUCTURAL CHARACTERIZATION OF INFLATABLE THIN-FILM BOOMS
}

\author{
Andrew R. Schnellt \\ Tennessee Technological University \\ Mechanical Engineering Department \\ Cookeville, TN 38501
}

\author{
Larry M. Leigh, Jr.市 \\ South Dakota St. University \\ Mechanical Engineering Department \\ Brookings, South Dakota
}

\author{
Michael L. Tinker* \\ Structural Dynamics and Loads Group/ED21 \\ Structures, Mechanics, and Thermal Department \\ NASA Marshall Space Flight Center \\ Huntsville, AL 35812
}

\begin{abstract}
Detailed investigation of the construction, packaging/deployment, foam rigidiation, and structural characterization of polyimide film inflatable booms is described. These structures have conviderable potential for use in space with solar concentraturs, solar sails, space power systems including solar arriys, and other future missions.

Numerous thin-film booms or struts were successfully constructed, inflated, injected with foam, and rigidized. Both solid-section and annular test articles were fabricated, using Kapton polyimide film, various adhesives, styrofoam end plugs, and polyurethane pressurized foam. Numerous inflation/deployment experiments were conducted and compared to computer simulations using the MSC/DYTRAN code. Finite element models were developed for several foam-rigidized struts and compared to modal test results.

Several problems encountered in the construction, deployment, and foam injection/rigidization process are described. Areas of difficulty included inadequate adhesive strength, cracking of the film and air leakage, excessive bending of the structure during deployment, problems with foam distribution and curing properties, and control of foam leakage following injection into the structure. Many of these problems were overcome in the course of the research.
\end{abstract}

\section{† Student of Mechanical Engineering \\ $\ddagger$ Graduate Research Assistant \\ * Structural Dynamics Lead Engineer; Associate Fellow AIAA}

Copyright $\Theta 2002$ by the American institute of Aeronautics and Astronautics, Inc. No copyright is asserted in the United States under Title 17, U.S. Code. The U.S. government has a royalty-free license to exercise all rights under the copyright claimed herein for Governmental purfoses. All other rights are reserved by the copyright owner.

\section{Introduction and Background}

Inflatable structures have been the subject of renewed interest in recent years for space applications such as communications antennas, solar thermal propulsion, and space solar power (Figs. 1-2). A major advantage of using inflatable structures in space is their extremely light weight. An obvious second advantage is on-orbit deployability and subsequent space savings in the launch configuration. However, it is widely recognized that for long-term use and survivability in space, inflatable structures must be rigidized by some means. This is particularly true for support structures such as booms and torus elements, where the pressure is relatively high compared to very large pressurized elements. Obviously, the higher the internal pressure required to support the inflatable structure, the greater the volume (and weight) of make-up gas that would have to be carried aboard the spacecraft if the structure were not rigidized.

Several of the mechanisms and materials for rigidizing inflatable structures that have been proposed are discussed in Ref. 1, including (1) thermoset composites, which can be cured thermally, by UV exposure, and by inflation gas reaction; (2) shape memory materials; (3) thermoplastic composites with plasticizer or solvent boil-off rigidization; (4) aluminum laminates that are rigidized by over-stressing; and (5) foam rigidization. The latter technique, foam rigidization, is the emphasis of this paper. The other techniques listed are currently receiving much more attention than foam rigidization, likely due to technical issues such as distribution or application of the foam within the structure. However, foam still appears to have enough potential to merit continued study, particularly for use with thin film materials such as Kapton, CP-1, Mylar, and others. An overview of historical studies and more recent investigations focused upon or involving foam rigidization is given in the following paragraphs. 


\section{Earliest Foam Rigidization Work (Primarily 1960's)}

Several very interesting carly studies on rigidization of inflatable thin-film solar concentrators were done in the 1960's. As early as 1960, papers appeared discussing inflated (also called expandable or erectable) structures for spaceflight applications. Goodyear Aircraft Company (Ref. 2) developed an inflatable "airmat" structure, which was derived from a cylindrical shape, and allowed construction of flattened, non-body-of-revolution shapes. Reference 2 also discusses leakage and meteroid/debris penetration problems, and discusses rigidization as a means of stabilizing the inflatable structure after initial deployment. Foam rigidization was emphasized in Ref. 2, and foam-filled "airmat" samples of density $0.3 \mathrm{lb} / \mathrm{cf}$ were shown in the paper. The paper also mentioned the possibility of using other systems to rigidize the fabric itself. Though the foam rigidization in Ref. 2 was applied to a fabric structure, clearly the technique can be also utilized with thin-film structures. A NASA Langley paper, appearing in 1960 (Ref. 3), also discusses the problem of micrometeorite puncture, and mentions two rigidization approaches for very large structures, including (1) hardening chemical foam introduced into cells or tubes following erection in space, and (2) automatic hardening skin that was originally flexible.

In 1961, an American Rocket Society paper (Ref. 4) was written by General Electric Company that discussed low-density polyurethane "foam-in-place" systems for rigidizing inflatable structures. The paper suggested three possible rigidization approaches---mechanical, physical, and chemical. Mechanical techniques envisioned by the authors involved attachment of prefoldable plastic or metallic structural members to the thin film structure, which would unfold and lock into position upon inflation of the structure. Physical and chemical approaches mentioned in the paper included (a) reactions in which a retardant would be evaporated, and (b) those in which polymerization would be generated by ultraviolet radiation. The focus of the paper was investigation of frozen foam-in-place reactants, which would be predistributed in the structure, and not require mixing and injection into the structure in orbit. Foaming behavior of different frozen powder formulations was studied for different pressures, and mechanical properties were determined for the samples produced.

An excellent overview of developments to the early 60 's with inflatable and other types of expandable structures was written in 1962 by the Flight Accessories Laboratory of the U.S. Air Force (Ref. 5). The paper cited work of all companies instrumental in expandable structures work to that time. The author discussed the inflatable Echo I satellite, and problems inherent with non-rigidized inflatable structures, pointing out the fact that long-term flight in a micrometeorite environment would entail a high probability of puncture. The paper included a discussion of "foamed-in-place" structures which would be rigidized by (1) spraying or injecting foam into the structure, (2) predistributing foam powder over or inside the structure to be thermally activated, and (3) using micro-encapsulated foam reactants applied to the inflatable structure surface, to be thermally activated by melting the capsule covers. As of 1962, several foamedin-place solar collectors had been fabricated on the ground, and a 7-ft diameter sphere had been foam-rigidized in a vacuum chamber.

\section{First Attempted Rigidization Work for Inflatable Concentrators}

Very significant work was reported in 1965 by Goodyear Aerospace (Refs. 6-7) and Hughes Aircraft (Ref. 8 ) for rigidization of solar concentrator mirrors. The work by Goodyear described in Ref. 6 concerned the development of a predistributed polyurethane foam (spread or pressed on), which was thermally activated in vacuum conditions. Predistributed foam was investigated to provide an alternative to use of injected foam and the associated requirement of a mixing/pumping system in space. The drawback to the thermally activated predistributed foam was the requirement of a heating system, such as hot wires. Solar concentrator mirrors up to $2 \mathrm{ft}$ diameter were foam-rigidized in vacuum. Contour measurements showed good quality, with less than 0.10 inch deviation from a perfect paraboloid for surface area, but certainly not optical quality. However, the approach showed reasonably good potential for actual use with flight solar concentrators. The authors recommended further development of predistributed foam material, and use of a different mirror film to minimize distortion during foam curing and rigidization. Rigidization of a $1.5-\mathrm{m}(5-\mathrm{ft})$ diameter concentrator by the same authors is described in Ref. 7.

Work by Hughes Aircraft (Ref. 8) involved development of two processes for in-space fabrication of 5-ft diameter inflatable rigidizable solar concentrator mirrors. The processes were (a) UV-activated polyester/fiberglass laminate, and (b) infrared-activated epoxy syntactic foam. The epoxy syntactic foam-rigidized concentrator was better optically, though the polyester laminate concentrator had greater strength. Both structures were found to be near-paraboloids with concentration efficiencies of $40-45 \%$ at area ratios of 900 . Surface angular deviation from best-fitting paraboloids was within 1.8 degrees. These results showed reasonably good promise for further development and practical use.

\section{More Recent Work Involving Foam Rigidization (1980's-90's)}

In 1990, L'Garde published a paper on inflatable concentrators for solar propulsion and space power applications (Ref. 9). The paper described rigidized torus and truss elements, which were to support two inflatable concentrators. For rigidization of the torus, two approaches were considered: (a) polyurethane foam to be injected into the torus to form either a solid or annular cross-section, and (b) fabric saturated with water-soluble gelatin which would harden upon water evaporation. In 1994, L'Garde reported development and testing of inflatable rigidized tubes constructed of aluminum foil sandwiched between layers of Kapton polyimide film. A coating was deemed necessary for the Kapton to provide atomic oxygen ( $\mathrm{AO}$ ) protection. It is noted that Kapton is 
considered by researchers to be one of the best films for space applications, particularly when coated for protection against $\mathrm{AO}$ effects.

Thiokol propulsion reported very significant work in 1996 (Ref. 10) related to foam inflation of rigidized fabric/resin truss structures. Although Thiokol has since concluded that fabric/resin rigidized trusses do not need foam to have adequate stiffness, the approach described is clearly applicable to thin-film cylinder and torus elements.

Jet Propulsion Laboratory published a 1998 paper (Ref. 11 ) describing development of an inflatable synthetic aperture radar (SAR). On-going or future technology efforts were mentioned for space rigidization of the inflatable support frame for the SAR, including approaches such as hydro-gel, stretched aluminum (foil), UV-cured epoxy coating, heat-cured epoxy coating, and open-cell foams.

Also in the late 1990's, ILC Dover published significant work on rigidization of inflatables (Refs. 1213). Reference 12 discussed several methods of rigidization, including thermal activi tion, passive cooling, UV exposure, inflation gas reaction, thin-wall aluminum (foil), and foam inflation.

The University of Kentucky conducted significant research in the late 1990's with foam-rigidization of thinfilm cylinders (Refs. 14-15). The approach utilized in these references was foam injection as opposed to predistributed foams referred to in the early 1960 's work.

\section{Fabrication Methodology for Thin- Film Booms}

Construction of polyimide film cylinders and annular tubes was done to (1) develop fabrication methods for foam-filled test articles to be used for modal and static loading tests, and to (2) uncover potential problems in the distribution of foam. The overriding objective of this work was to develop a reliable method for manufacturing these thin-film structures. An aspect ratio of 10 was chosen to allow testing for consisient comparison with booms constructed and rigidized using other technologies. For ease of construction, an outside diameter of 3.5 inches was chosen, making the length of the desired test article 35 inches. Initial fabrication relied heavily on a process developed by Duke University (Ref. 16). Their work dealt with fabrication and testing of air-filled (unrigidized) inflatables, and their fabrication methodology was an excellent first step.

In the basic method of construction for cylinders (and inner/outer sleeves for tubes) Kapton(C) was wrapped around a PVC pipe, which served as a mandrel for the inflatable. Table 1 lists some of the film property data available from the manufacturer. Both silicone and twopart epoxy adhesives were investigated for the securing of the overlap seam, but it was found that the silicone lacked the strength required for repeated pai-king and deployment of the structures. Once the adhesive had set up for a few minutes, the article was slid off the mandrel and allowed to dry over night. Styrofoam material was used for end caps, which were cut using a drill press with a hole saw attachment, and then assembled in each cylinder or tube using a silicone adhesive. One cap for each test article was drilled to accommodate air and foam injection hoses.

\section{Inflation/Deployment Experiments and Simulations Using MSC/DYTRAN}

An attempt was made to model the inflation process of these structures. The real effort was to determine if this process could be modeled using MSC/DYTRAN software, and what it took to create such a model. The original process was to "draw" the structures in their deflated form, which was an extremely difficult and time-consuming task. One of the first inflation models created in this fashion (Fig. 3) was a z-fold model, which was created by drawing an end cylindrical strut that flattened down to a fold after 3 inches then was folded back and forth on itself 10 times. During the inflation process, the model showed how unstable this type of packaging was, so an alternative folding scheme was investigated. This consisted of constructing the model of a strut, compacted down along the axial direction in a spiral fashion. The model in Figure 4 shows a strut 30 inches long and with a 3" diameter compressed down to 4 " in length.

The deployment modeling of the struts, at this time, did not lead to a lot of data to compare to existing results, but instead was an exercise to see if this process could be done in MSC/DYTRAN. It was discovered that drawing the structure as it exists, in its final inflated state, and then applying "folding" forces to the structure as it was deflated, proved to be an easier way to develop more complex folded structures. Once the structure was fully deflated and folded, the forces were removed and the gas flow was reversed and the structure was inflated. This approach required additional computational time to accomplish the deflation process, but required a lot less CAD time to draw, as compared to drawing the objects in an initially deflated state. Another important parameter was the range of flow rates required to accomplish the inflation without popping or exploding the structure. For example, as mentioned previously the $z$-fold (unless under very low inflation rate) caused the strut to swing wildly until full inflation was achieved.

The next step in the investigation of MSC/DYTRAN modeling of structure inflation is to compare the results to test data. Once the process is verified to actual small-scale prototypes, the process can be scaled up to simulate large structures that would be impractical or impossible to inflate on earth. Deployment control could also be modeled and investigated using DYTRAN. For example, the $z$-fold packaging could be revisited with deployment control. 


\section{Foam Injection and Rigidization of Thin-Film Cylinders and Tubes}

Foam injection was carried out using commercially available spray-on polyurethane foam. Three commercially available foams were used in this study. Table 2 lists some of their properties. With similar properties, both brands of one-part foam allowed rigidization of tubes with approximately the same drying time and final rigidity. The two-part foam was too difficult to use in these initial studies. Initial testing revealed that the rapid cure rate opened several design issues concerning adequate distribution of the foam. However, it is realized that fairly rapid cure rates (on the order of several minutes) are desirable in orbit so that the possibility of disturbances preventing complete rigidization can be minimized.

Use of one-part foam for rigidization in the laboratory was relatively straightforward. The foam was injected until the tube was seventy percent filled. The tube ends were then placed in compression and the tube was dried vertically. The one-part foam typically takes an entire day to dry. Figures 5 and 6 are photographs of a foamrigidized annular tube.

Foam distribution was one of the most difficult problems that arose during fabrication. Once the foam exits the distribution hose, it expands radially. Tests using a rapid curing two-part foam showed that use of a single injection location results in blockage of the filling space before an entire structure can be injected with foam. For this reason, one-part slow curing foam was used in most of the laboratory demonstrations.

\section{Finite Element Modeling Approach and Results for Foam-Filled Struts}

One problem that became apparent at a very early stage of modeling was the difficulty of determining material properties for the foam. Properties for higher density foam were commonly available in the literature, but not for the low-density foam that was used in this study. Finally, after extensive research, it was found that most of the foam properties could be determined if the composition of the foam was known as well as its density (Ref 17). The most important information that came out of this research was that the elastic modulus can be described by the following equation, for low-density foam (below $4 \mathrm{lb} / \mathrm{ft}^{3}$ ):

$$
E(p s i)=573.5 D^{1.1501 x}
$$

where $\mathrm{D}$ is density in $\mathrm{lb} / \mathrm{ft}^{3}$, and $\mathrm{E}$ is the modulus of elasticity. This approximation proved to be a good starting point. When compared with available experimental results for foam-rigidized structures, it was found that the formula produced a much stiffer model than what was observed in test. Doing some comparison of results from the FEM model of the structure and the results from the test, a closer approximation was made when the equation was adjusted to

$$
E=318.59 D^{1.1508}
$$

After the elastic modulus was determined, the modeling could begin, and there were many different struts that where modeled. One example of a strut modeled was a 6" diameter, 6' long foam-filled strut. The foam density of this strut was $2 \mathrm{lb} / \mathrm{ft}^{3}$. Based on this density, Eq. (2) gave a modulus value of 707.08 psi. Poisson's ratio for this foam is 0.30 .

Another type of strut that was considered was an annular foam-filled tube. The reason for going to the annular tube geometry was to minimize the weight without reducing the overall stiffness and strength of the structure to any great degree. The particular strut that was modeled had the following properties: length $=12$ ", outside diameter $=3.5^{\prime \prime}$, inside diameter $=3 "$, modulus $=$ $1273 \mathrm{psi}$, density $=2 \mathrm{lb} / \mathrm{ft}^{\wedge} 3$, and Poisson's ratio $=0.30$.

The results obtained for the rigidized struts will be compared to the results of ongoing modal testing of struts, when the tests are complete. One observation of interest was that the thin layer of Kapton (0.002 in) made the structure considerably more stiff and increased the natural frequencies significantly (Table 3 ). In light of this discovery all the subsequent models included this layer of Kapton, with the foam contained inside. Also included for in Table 3, for comparison to finite element results, are the frequencies from analytical beam theory for the bending modes.

\section{Summary and Observations}

A method for the manufacture of annular foamrigidized structures was developed. Several test samples for modal and structural testing were fabricated. Several design issues raised from this research were discussed, including foam distribution, folding and packaging of inflatables, and sizing for future annular inflatables.

An obvious area for more study deals with the determination of the inner and outer diameters of the annular cross-section for a deployable tube. Desirable weight, length, and strength data need to be determined, so adequate dimensions can be determined.

Folding and packaging of test articles is another issue for study. Two methods of folding were investigated: accordion folding and roll-out folding. Both seem feasible for use in a controlled deployment of an inflatable. An inflatable using the roll-out method could employ a seam of Velcro or low-powered magnets along the inside of the fold. Accordion-folded tubes could employ the use of friction between the structures and their deployment canisters. Folding methodologies should also take into account foam deployment methods. If a hose is employed to distribute foam, the possibility of including the hose in the folding should be explored.

Following the construction of further test samples, modal and static load tests will be carried out. Further deployment and rigidization tests will need to be carried out in vacuum chambers to better simulate the orbital environment. Obviously, the materials utilized to make 
test articles for this research have not been proven in vacuum and microgravity environınents.

\section{Acknowledgments}

Jason "Red" Huddleston is acknowledged for his assistance in machining of rigid foam parts for the test articles constructed in this study.

\section{References}

1. Cadogan, D., "Rigidization Mechanisms and Materials", in Gossamer Spacecraft: Membrane and Inflatable Structures Technology for Space Applications, AIAA Progress in Astronautics and Aeronautics, Vol. 191, Ed. Christopher Jenkins, American Institute of Aeronaulics and Astronautics, Reston, VA, 2001, pp. 257-279.

2. Sandgren, F.B., and Harris, J.T., "Application of Inflated, Expandable Structures to Orbital Flight and Re-Entry", American Rocket Society Paper 109360, Proceedings of the Structural Design of Space Vehicles Conference, Santa Barbara, CA, April 6-8, 1960.

3. Schnitzer, E., "Erectable Torus Manned Space Laboratory", American Rocket Society Paper 108860, Proceedings of the Structural Design of Space Vehicles Conference, Santa Barbara, CA, April 6-8, 1960.

4. Hefty, R.W., Hersh, H.R., Shenker, L.H., "The Rigidization of Inflatable S/ructures in Space", American Rocket Society Piper 2034-61, Space Flight Report to the Nation. New York, NY, October 9-15, 1961.

5. Forbes, F.W., "Expandable Structures for Aerospace Applications", American Rocket Society Paper 2697-62, Proceedings of the $17^{\text {th }}$ Annual Meeting and Space Flight Exposition, Los Angeles, CA, November 13-18, 1962.

6. Jouriles, N., and Welling, C.E., "Development of a Predistributed Azide Base Polyurethane Foam for Rigidization of Solar Concentrators in Space", NASA CR-235, 1965.

7. Jouriles, N., Welling, C.E., and Kryah, J.C., "Rigidization of a 1.52-Meter Diameter Inflatable Solar Concentrator in Vacuum with Associated Material Studies and Fabrication Techniques", NASA CR-66114, 1966.

8. Schwartz, S., and Bagby, J., "Rigidized Inflatable Solar Energy Concentrators", NASA CR-254, 1965.

9. Grossman, G. and Williams, G., "Inflatable Concentrators for Solar Propulsion and Dynamic Space Power", Journal of Solar Energy Engineering, Vol. 112, pp. 229-236, Nov. 1990.

10. Lester D., and Cannon. D., "Foam Inflated Rigidized Truss Structure Diveloped for an SRS Technologies Solar Concentritor", Proceedings of the 1996 International Solar Energy Conference, ASME, New York, NY, pp. 451-458, 1996.

11. Lou, M.C., Feria, V.A., and Huang, J., "Development of an Inflatable Space Synthetic Aperture Radar", AIAA Paper 98-2103, Proceedings of the $40^{\text {th }}$ Structures, Structural Dynamics, and Materials Conference, St. Louis, MO, pp. 27832788, April 12-15, 1999.

12. Cadogan, D., Grahne, M., and Mikulas, M., "Inflatable Space Structures: A New Paradigm for Space Structure Design", IAF-98-I.1.02, Proceedings of the $49^{\text {th }}$ Congress of the International Astronautical Federation, Melbourne, Australia, Sept. 28-Oct. 2, 1998.

13. Cadogan, D.P. Grahne, M.S., Sandy, C.R., Harvey, T.J., and Veal, G.,"Deep Space 4/Champollion Inflatable Solar Array", Proceedings of the $40^{\text {th }}$ Structures, Structural Dynamics, and Materials Conference, St. Louis, MO, April 12-15, 1999.

14. Hobbs, K.P., Smith, S.W., and Main, J.A., "PostFlight Testing and Analysis of Zero-G Foam Rigidized Struts", AIAA-99-1524, Proceedings of the $40^{\text {th }}$ Structures, Structural Dynamics, and Materials Conference, St. Louis, MO, April 12-15, 1999.

15. Main, J.A., Smith, S.W., and Chapman, A.L..,"Damage Tolerance and Assessment of FoamInflated Aerospace Structures, Journal of Aerospace Engineering, Vol. 12, No. 3, pp. 98-104, July 1999.

16. Holland, D.B., Virgin, L.N, Slade, K.N., and Tinker, M.L., "Geometric Scaling Properties of Inflatable Structures for Use in Space Solar Power Generation", AIAA $43^{\text {rd }}$ Structures, Structural Dynamics, and Materials Conference and Gossamer Spacecraft Forum, April 22-25, 2002, Denver, CO.

17. Bender, R. J., "Handbook Of Foam", Lake Publishing Corporation, Libertyville, IL, 1965.

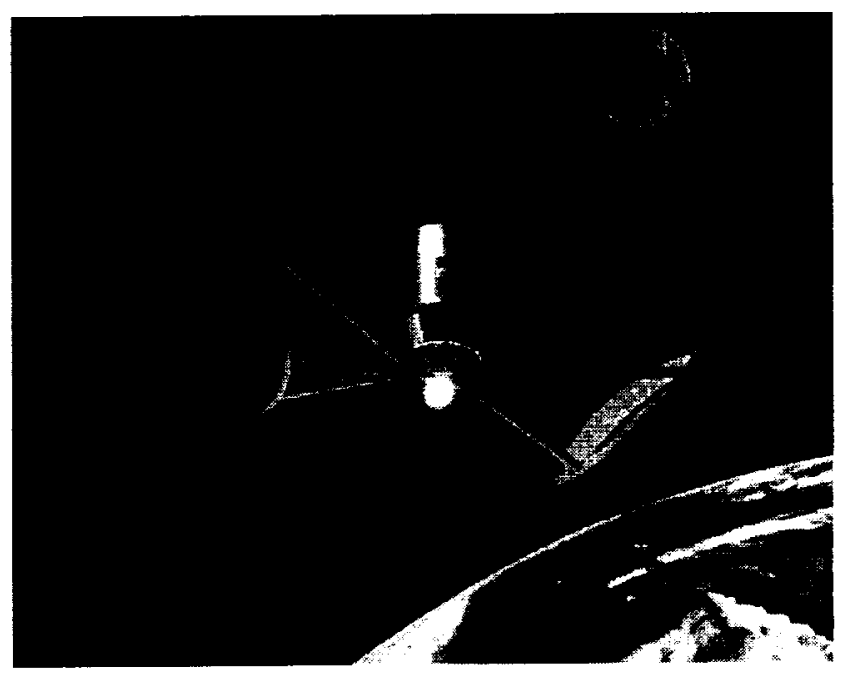

Figure 1. Concept for Solar Orbital Transfer Vehicle Utilizing Inflatable Solar Concentrators 


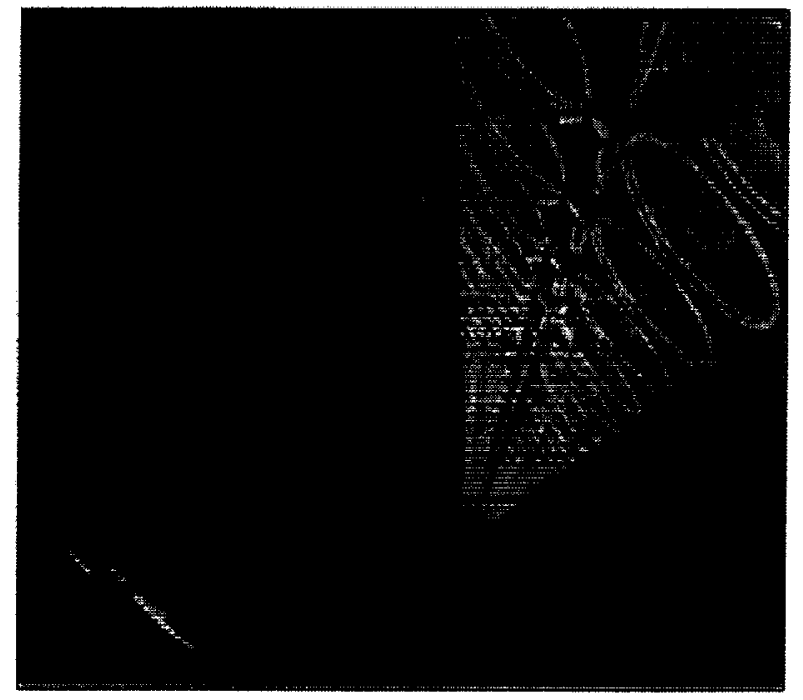

Figure 2. Space Solar Power Concept Based on Inflatable Structures

\begin{tabular}{|l|c|}
\hline Tensile Strength & $33500 \mathrm{psi}$ \\
\hline Density & $1.42 \mathrm{~g} / \mathrm{mL}$ \\
\hline Tensile Modulus & $370000 \mathrm{psi}$ \\
\hline Poisson's Ratio & 0.34 \\
\hline
\end{tabular}

Table 1. Properties of Kapton 100-HN Film

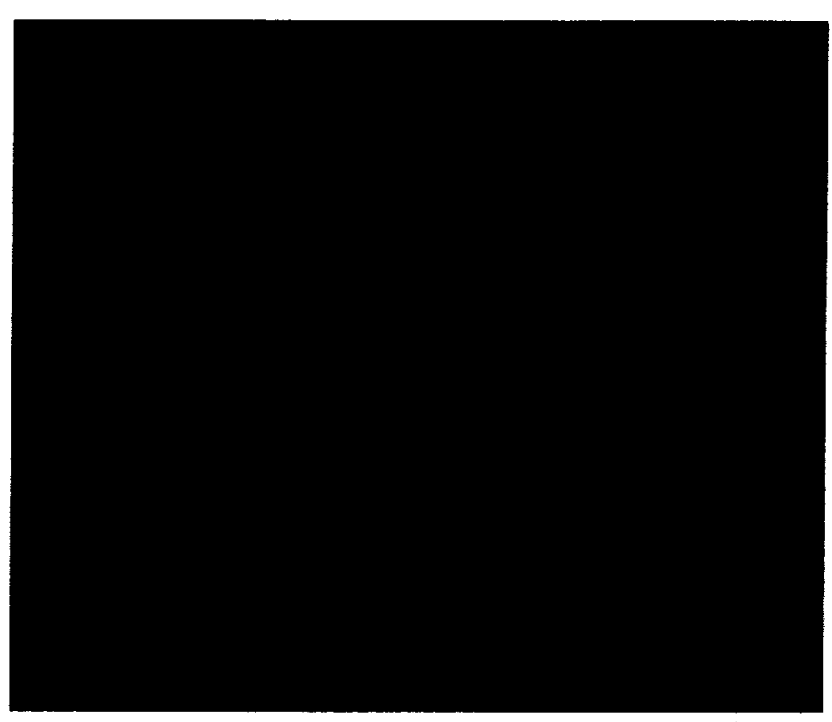

Figure 3. FEM Model of Z-Folded Strut

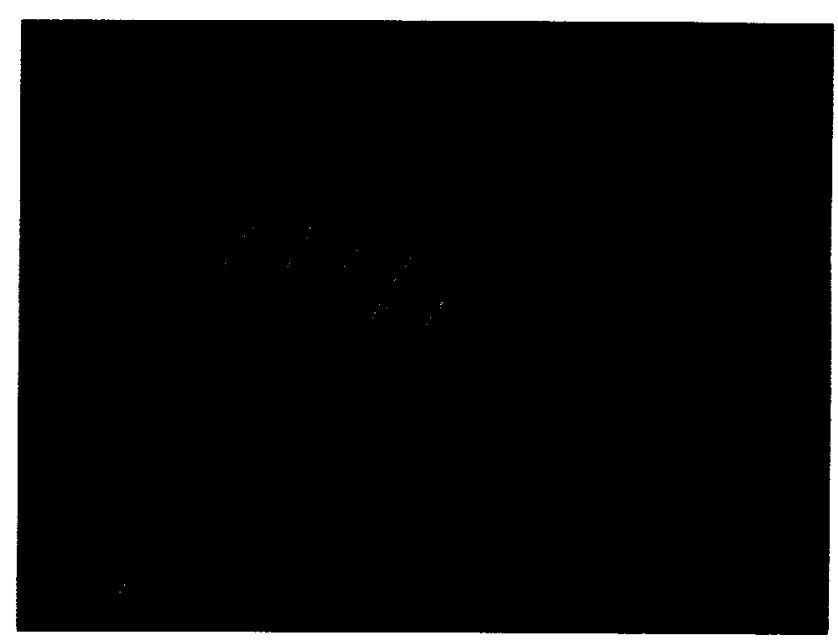

Figure 4. FEM Model of Accordion-Folded Strut

\begin{tabular}{|c|c|}
\hline $\begin{array}{l}\text { Handi-Foam@ Two Component } \\
\text { II-12 s }\end{array}$ & Quick-Cure \\
\hline Density & $1.75 \mathrm{lbs} / \mathrm{ft} 3$ \\
\hline Tensile Strength & $46 \mathrm{psi}$ \\
\hline Compressive Strength & $23 \mathrm{psi}$ \\
\hline Expansion Time & $0.5-1 \mathrm{~min}$. \\
\hline Theoretical Yield & $1 \mathrm{ft} 3$ \\
\hline $\begin{array}{l}\text { Handi-Foam OOne Component } \\
\text { Polyurethane Foam s }\end{array}$ & \\
\hline Density & $1.2 \mathrm{lbs} / \mathrm{ft} 3$ \\
\hline Cure Time & $12-24 \mathrm{hrs}$ \\
\hline Theoretical Yield & $0.625 \mathrm{ft} 3$ \\
\hline Great Stuff $\odot$ Polyurethane Foa & $m^{6}$ \\
\hline Density & $1.7 \quad \mathrm{lbs} / \mathrm{ft} 3$ \\
\hline Tensile Strength & $22.3 \mathrm{psi}$ \\
\hline Compressive Strength & $9.7 \mathrm{psi}$ \\
\hline
\end{tabular}

Table 2. Properties of Commercially Available Foams

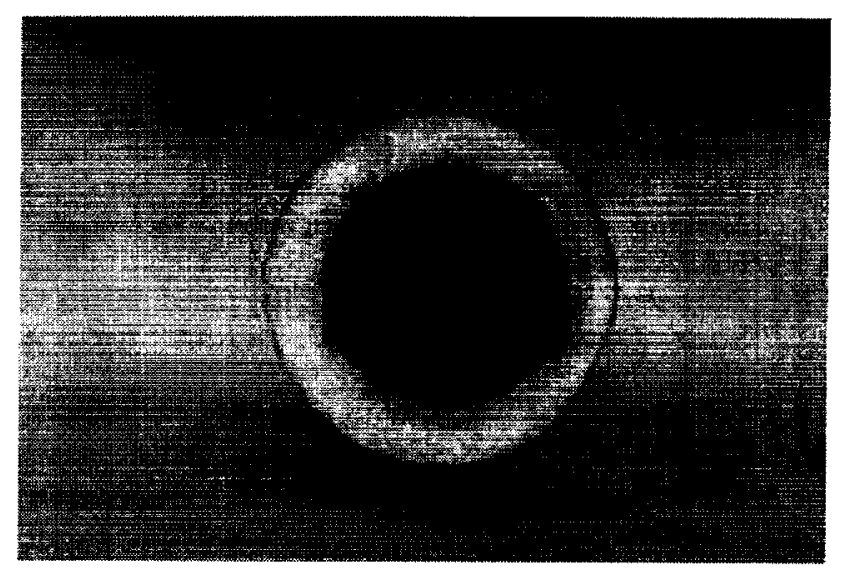

Figure 5. Foam-filled Annular Tube 


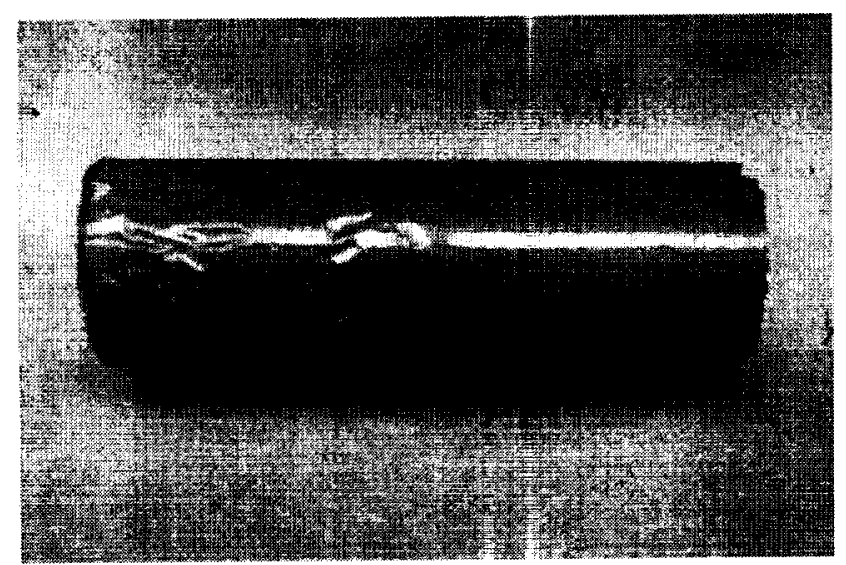

Figure 6. Foam-Rigidized Tube

\begin{tabular}{|c|c|c|c|c|}
\hline $\begin{array}{l}\text { Mode } \\
\text { Shape }\end{array}$ & $\begin{array}{l}\text { With } \\
0.002 . \\
\text { Kapton } \\
\text { Layer }\end{array}$ & Without & $\begin{array}{l}\text { Beani } \\
\text { Theory }\end{array}$ & Description \\
\hline 1 & 66.42 & 35.77 & 68.5 & $I^{s}$ Bending \\
\hline 2 & 179.31 & 97.73 & 190.4 & $2^{\text {ind }}$ Bending \\
\hline 3 & 341.39 & 187.3 & 373. & $3^{\text {ro }}$ Bending \\
\hline 4 & 404.81 & 229.4 & & $T^{M}$ Breathing \\
\hline 5 & 544.18 & 302.6 & 616 & $4^{\text {th }}$ Bending \\
\hline 6 & 571.07 & 387.16 & & $1^{\text {st Axial }}$ \\
\hline 7 & 779.67 & 440.05 & 9213 & $5^{4 n}$ Bending \\
\hline 8 & 809.28 & 458.78 & & $2^{\text {no }}$ Breathing \\
\hline
\end{tabular}

Table 3. Comparison of Natural Frequencies for FEM of Strut With and Without Kapton Film Layer, and for Beam Theory Predictions With Film Layer 
